\title{
Deckschichten verhindern Reibung von Verbindungselementen
}

$M$ it den Deckschichten Geokote und Plus VLh hat die NOF Metal Coatings Europe verbesserte Schichten für Schrauben und Verbindungselemente auf den Markt gebracht. Die Plus VLh, eine Weiterentwicklung der bewährten Plus VL-Beschichtung, zeichnet sich durch einen verbesserten Reibwert aus und eignet sich damit sehr gut für Schrauben, insbesondere Vielfachverschraubungen in Aluminium und für den Einsatz auf KTL. Verbessert wurde auch das Warmlöseverhalten. Zudem werden Stick-SlipProbleme vermieden. Die neue Deckschicht wurde speziell für die Geomet 321-Grad-A-Grundschicht entwickelt und wird in einer Schicht aufgetragen. Sie kann auf vielen Erzeugnissen der Schraubenindustrie angewendet werden und erfüllt auch die Ansprüche der deutschen Automobilindustrie. Die Freigabe für dieses Produkt hat bereits begonnen.

Die Deckschicht Geokote wird zurzeit serienmäßig auf AuBenteilen von Fahrzeugen benutzt, zum Beispiel auf Schließsystemen für Wagentüren und auf Motorhaubenverriegelungen. Sie zeichnet sich durch eine hohe chemische Beständigkeit aus (Chlorwasserstoff-, Phosphor-, Schwefelsäure) und ist abriebfest.

www.nofmetalcoatings.com

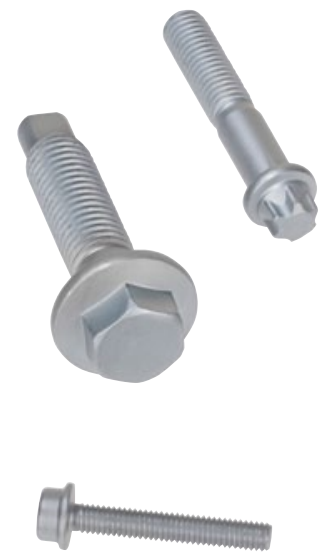

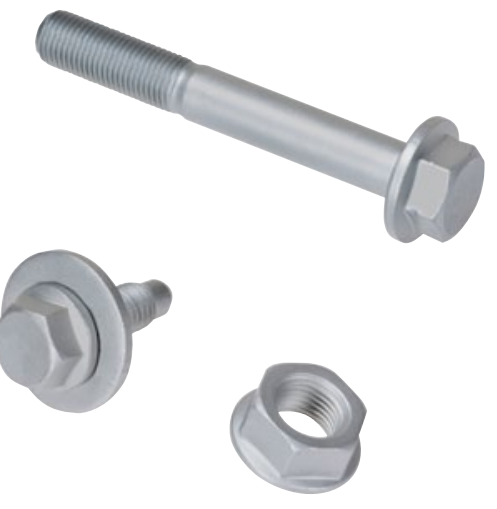

\section{Punktuelle Profilmessung auf vielen Oberflächen}

Einester ne sachgemäße und effektive Vorbereitung der Oberfläche vor dem Beschichten ist unabdingbar. In diesem Zusammenhang muss sichergestellt sein, dass die Oberfläche die richtige Rauheit, also das richtige Profil besitzt. Dieses wird bislang unter anderem mit Oberflächenvergleichsscheiben oder dem Testex-Tape ermittelt. Eine handliche und robuste Alternative hat jetzt die Elcometer Instruments mit der 224-Profilmessuhr entwickelt. Durch eine punktuelle Messung kann die Rautiefe eines Bauteils damit schnell und unkompliziert ermittelt werden. Die beständi- gen, reproduzierbaren und genauen Messergebnisse machen es möglich, Qualitätsmängel direkt vor Ort aufzudecken. Die Profilmessuhr ist mit integrierter oder separater Sonde erhältlich. Die externen Messköpfe können dank ihrer Standfüße auch für konvexe Substrate wie etwa für Pipelines verwendet werden. Somit kann das Gerät auf vielen ebenen und gekrümmten Oberflächen verwendet werden. Der Messkopf verfügt über eine robuste Wolframkarbid-Messspitze für bis zu 20000 Messungen, die der Anwender selbst austauschen kann. Geräte mit integrierter Sonde sind ideal für die Bedienung mit einer Hand, da sich das Gerät während der Messung dank der breiten Auflagefläche der integrierten BigfootTM-Sonde stabil halten lässt. Der Speicher fasst je nach Modell bis zu 150000 Messwerte in 2500 Losen. Der Messbereich beträgt bei einer Messgenauigkeit von +/- $5 \%$ $500 \mu \mathrm{m}$. Je nach Bedarf ist dieses Gerät als Basismodell oder als Topmodell mit Speicher und PC-Übertragung erhältlich. Wie der Hersteller betont, ist die Profilmessuhr eine preisgünstige Alternative zu teureren Tastschnittgeräten.

Tel. 07361 528060, www.elcometer.de

\section{Erweitertes Sortiment intelligenter elektrostatischer Luftspritzpistolen}

$\mathrm{M}$ it der neuen Produktreihe Pro Xp hat die Firma Graco neue leichte und effiziente elektrostatische

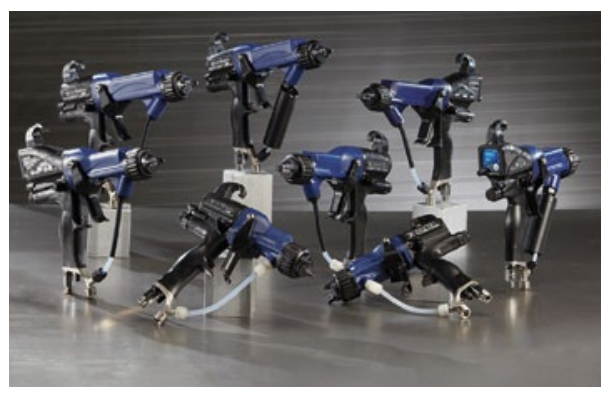

Luftspritzpistolen und AirAssist-Spritzpistolen auf den Markt gebracht. Die kom pakte 40-kV-Boosterpistole beispielsweise erreicht den Auftragswirkungsgrad einer herkömmlichen 60-kV-Pistole. Zum Sortiment gehören ferner eine kleine und leichte 60-kV-Air-Assist-Spritzpistole sowie verschiedene Pistolen mit hoher elektrischer Leitfähigkeit zum Spritzen von Materialien mit niedriger Leitfähigkeit. Die Geräte kommen ohne schweres Netzkabel aus und verfügen über einen ergonomischen Handgriff. Zudem sind sie mit einer intelligenten Steuerung zur Analyse der Leistung, zur Spannungsanpassung und zur Fehlersuche ausgestattet. Dank der neuen Air-Assist-Düsen und Luftkappen entsteht ein hochwertiges Finish.

www.graco.com 